\title{
Effects of hydroalcoholic extract of Rosa damascena Mill on the cardiac angiogenesis in diabetic male rats
}

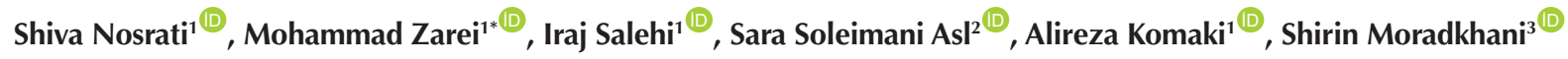 \\ ${ }^{1}$ Department of Physiology, School of Medicine, Hamadan University of Medical Sciences, Hamadan, Iran. \\ ${ }^{2}$ Department of Anatomy, School of Medicine, Hamadan University of Medical Sciences, Hamadan, Iran. \\ ${ }^{3}$ Department of Pharmacognosy, School of Pharmacy, Hamadan University of Medical Sciences, Shahid Fahmideh Boulevard, \\ Hamadan, Iran.
}

*Corresponding Author: Mohammad Zarei; Department of Physiology, School of Medicine, Hamadan University of Medical Sciences, Hamadan, Iran. Tel: +989183174335; Fax: +9838380208; Email: mmmzarei1@gmail.com

\begin{abstract}
Background and aims: The cardiac angiogenesis is one of the complications of diabetes. The oxidative stress occurs when there is an imbalance between the production of free radicals and antioxidant defense of the body. In diabetes mellitus, hyperglycemia induces increased oxidative stress through biological processes. Diabetes is also associated with reduced antioxidant defense by reducing glutathione, catalase, and superoxide dismutase. Rosa damascena Mill has antioxidant properties. This study aimed to investigate the effects of hydroalcoholic extract of $R$. damascena Mill on cardiac angiogenesis in diabetic rats.

Methods: In this experimental study carried out in 2016, a total of 48 adult male Wistar rats (190-200 g) were randomly divided into 8 groups $(n=6)$ including control, extracts $(200,400$, and $1000 \mathrm{mg} / \mathrm{kg})$, diabetic, and diabetic plus extracts $(200,400$, and $1000 \mathrm{mg} / \mathrm{kg})$. Diabetes was induced by intraperitoneal (i.p.) injection of streptozotocin (STZ) $(50 \mathrm{mg} / \mathrm{kg}$ ) and the rats were gavaged with different doses of extract for 30 days. At the end of the treatment, serum levels of vascular endothelial growth factor (VEGF) were determined by enzymelinked immunosorbent assay and the rat hearts were removed for immunohistochemistry study.

Results: The treatment with hydroalcoholic extract of $R$. damascene Mill had no significant effect on cardiac capillary density $[F(7$, $40)=0.5, P>0.05]$ and the serum levels of VEGF $[F(7,40)=0.406, P>0.05]$. However, there was no significant difference in blood glucose level in extract groups compared to control rats as well as diabetic plus extract groups compared to diabetic rats $[F(7,40)=0.787, P>0.05]$. Conclusion: According to our results, the hydroalcoholic extract of $R$. damascene Mill had no effect on cardiac angiogenesis in the normal and diabetic subjects. These findings were probably due to the insufficient amounts of effective ingredients, especially flavonoids, in this plant, or the duration of extract administration.

Keywords: Angiogenesis, Diabetes mellitus, Rat, Rosa damascena Mill, Vascular endothelial growth factor
\end{abstract}

Received: 22 August 2019, Accepted: 12 December 2019, ePublished: 29 April 2020

\section{Introduction}

Diabetes mellitus is a chronic metabolic disorder characterized by increased blood glucose levels due to insulin hormone deficiency or reduced body responsiveness (1). High glucose levels in the body over a long period of time can cause damage to very small veins in the body that can affect various organs such as the kidneys and eyes. Diabetes is also directly associated with an increased risk of cardiovascular diseases (2). Angiogenesis is a process through which new blood vessels form from pre-existing arteries that are essential for the growth and development of body tissues $(3,4)$ and can be affected by diabetes. Diabetes can decrease or increase this process in some organs of the body, such as the heart, by disturbing the balance between stimulatory factors and angiogenesis inhibitors (5). In fact, diabetes reduces the rate of this process by altering the expression of several genes involved in angiogenesis, such as Vascular endothelial growth factor (VEGF) (6). About $80 \%$ of the world's population live in developing countries where they tend to use medicinal plants for treating the diseases because of the high cost of synthetic drugs, lack of access to them, and their complications (7). Rosa damascena Mill as one of the well-known medicinal plants in traditional medicine due to its high phenolic content, has strong antioxidant, anti-diabetic, anti-inflammatory, anti-aging, and sedative properties (8). The active ingredients of $R$. damascena Mill include kaempferol, quercetin, geranial, eugenol, citronelle, myrcene, phenylethyl alcohol, nonadecane, eicosane, triclosan, geranyl acetate, carboxylic acid, and so on (9). Given that antioxidants seem to play a role in modulating the angiogenesis in the tissues as well as the decrease or increase of such process (10), this study aimed to investigate the effects of hydroalcoholic extract of this

(C) 2020 The Author(s); Published by Shahrekord University of Medical Sciences. This is an open-access article distributed under the terms of the Creative Commons Attribution License (http://creativecommons.org/licenses/by/4.0), which permits unrestricted use, distribution, and reproduction in any medium, provided the original work is properly cited. 
plant on the angiogenesis process after inducing diabetes in rats.

\section{Materials and Methods}

\section{Animals and the experimental groups}

All animal procedures were conducted in accordance with guidelines established by the Research Ethics Committee of Hamadan University of Medical Sciences. Forty-eight male Wistar rats (200-250 g) were purchased from Pasteur Institute (Tehran, Iran) and were housed in groups at $22 \pm 2^{\circ} \mathrm{C}$ under a 12 -hour light/12-hourdark cycle. Rats had free access to water and standard chow. They were randomly divided into eight groups ( 6 animals per group) as follows: control (normal diet), extract groups (200, 400, and $1000 \mathrm{mg} / \mathrm{kg}$ ), diabetic, and diabetic + extract (200, 400 , and $1000 \mathrm{mg} / \mathrm{kg}$ ). The extract was daily administered by oral gavage for 1 month. Then, they underwent surgery and the experiments were performed.

The rats with normal blood glucose levels were included in the study; however, non-diabetic rats were eliminated during tests. This study was approved by the Vice-chancellor for Research and Technology of the Hamadan University of Medical Sciences (IR.UMSHA.REC.1394.68).

\section{Chemicals and Reagents}

Rosa damascena Mill was purchased from a flower market (Iran). Ethanol, formalin solution, paraffin, and xylol were purchased from Merck Co. (Germany). Streptozotocin (STZ) was purchased from Sigma Co. (USA). Sodium chloride $0.9 \%$ was purchased from Darou Pakhsh Co. (Iran). $\mathrm{H}_{2} \mathrm{O}_{2}$ solution (5\%) was purchased from Behsaman Co. (Iran). The $\mathrm{CD}_{31}$ primary antibody, EnVision secondary antibody, as well as PBS, R.S, DAB, and hematoxylin solutions were purchased from DaKo Co. (Denmark). CK-E30634 ELISA kit was purchased from Biopharm Co., USA.

\section{Induction of diabetes}

In this study, type 1 diabetes was induced in animals by a single intraperitoneal injection of STZ $(60 \mathrm{mg} / \mathrm{kg})$, which causes partial or total degradation of pancreatic beta cells. After 48 hours, blood samples were collected from the tail of rats, and they were considered as diabetic rats in case of blood glucose greater than $250 \mathrm{mg} / \mathrm{dL}$ (11). Blood glucose levels in all rats were evaluated before grouping and after STZ injection to ensure diabetes induction and then were measured weekly.

\section{Preparation of extract}

For the preparation of the hydroalcoholic extract of $R$. damascena Mill, petals of the plant were purchased from a florist (Hamadan, Iran) in spring 2016. These petals were dried in a room free of sunlight and then ground into a powder. The powder was then dissolved in 98\% ethanol and extracted using distilled water and ethanol $(1: 1 \mathrm{v} / \mathrm{v})$ as a solvent. The resulting extract was filtered and concentrated under reduced pressure in a rotary evaporator. It was finally freeze-dried at $-80^{\circ} \mathrm{C}$. The extract was dissolved in water and prepared fresh daily and the extract doses were administered for 1 month. The doses of the extract were chosen according to previously published reports $(12,13)$. Similarly, in each gavage, $1 \mathrm{~mL}$ of the intended volume was prescribed for the extract-treated groups (at doses of 200, 400 , and $1000 \mathrm{mg} / \mathrm{kg})(14,15)$.

\section{The removal of heart tissue and serum preparation}

After being anesthetized, the rats underwent chest surgery and blood samples were taken directly from the heart and serum isolation was carried out to measure VEGF. Then, the heart of rats was removed from the body and fixed in the formalin solution after being washed with normal saline. The heart tissues were processed in the autotechnicon machine and were embedded in paraffin to measure capillary density using the immunohistochemistry technique.

\section{Measurement of VEGF}

The concentration of VEGF in rat serum was measured by ELISA and CK-E30634 kit (Biopharm, USA). For this purpose, after preparation of samples and standards, $40 \mu \mathrm{L}$ of the standard serum sample was added, followed by 10 $\mu \mathrm{L}$ of biotin solution, and $50 \mu \mathrm{L}$ of HRP linked polyclonal antibody was added to each well of microplate previously coated with monoclonal antibodies. The microplate was then left at $37^{\circ} \mathrm{C}$ for 60 minutes. The microplate was washed with the washing solution for 5 times, then chromogen $\mathrm{A}$ and $\mathrm{B}$ solutions were added to the wells and the microplate was left at $37^{\circ} \mathrm{C}$ for 10 minutes. Afterwards, $50 \mu \mathrm{L}$ of stop solution was added to the wells for color development. Finally, the optimum density was determined at $450 \mathrm{~nm}$ wavelength using a microplate reader and the concentration of VEGF was expressed in ng/L (16).

\section{Measurement of capillary density}

For this purpose, the primary antibody $\mathrm{CD}_{31}$ was used as an indicator of endothelial cells in cardiac capillaries. The paraffin blocks of heart tissue were sliced into 3-micron blocks and placed on a slide. The slides were left in the oven and then in xylol. The resulting slides were placed in PBS solution and then in R.S solution. After being placed in distilled water, the slides were placed in $\mathrm{H}_{2} \mathrm{O}_{2}$ solution (5\%) and the distilled water and PBS solution. An appropriate amount of antibody was placed on the slices while adding the primary antibody. The slides were then washed. In the next step, the secondary antibody was added to the slices, and the slides were washed and placed in a PBS buffer. Then, the chromogen was placed on the slices and the washing process was carried out in distilled water and PBS solution. Hematoxylin was added to the slices and the slides were washed in the next stage. 
Ultimately, the slides were dehydrated, placed in xylol, and prepared for morphology detection. Ten microscopic fields from each tissue preparation were selected and by counting endothelial cells, the capillary density was determined and expressed as the number of endothelial cells per $\mathrm{mm}^{2}$.

\section{Statistical analysis}

Data were analyzed using SPSS version 16.0 software and were used by unpaired $t$-test and one-way analysis of variance (one-way ANOVA) followed by Tukey's post hoc test. A $P$ value less than $0.05(P<0.05)$ was considered statistically significant. Data were expressed as mean \pm SEM.

\section{Results}

\section{Evaluation of blood glucose levels}

In Figure 1, we showed the comparison of the mean blood glucose levels in different groups at the beginning of the experiment and during the first to the fourth weeks. There was no significant difference $[\mathrm{F}(7,40)=0.777, P>0.05]$ between the control group and normal rats (that only received the extract for one month). Moreover, there was no significant difference $[F(7,40)=0.652, P>0.05]$ between the diabetic group and the diabetic + extract groups (that received the extract for one month). However, in the diabetic group and the diabetic + extract groups, due to the damage of beta-pancreatic cells, changes in the blood glucose level were observed during four weeks [F (7, 40) $=53.25, P<0.001]$.

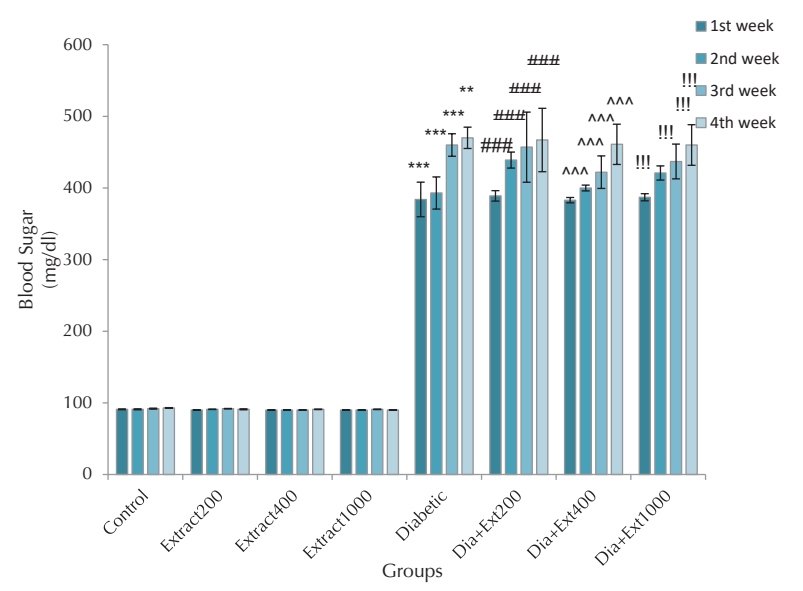

Figure 1. The Mean Blood Glucose Concentrations in Different Groups During the First to Fourth Weeks of the Experiment. Results showed that there was no significant difference in blood glucose levels between the control group and the extract groups $[F$ ( 7 , $40)=0.777, P>0.05]$, as well as between the diabetic group and the diabetic + extract groups $[F(7,40)=0.652, P>0.05]$. However, significant differences in blood glucose levels were observed between the control group and the extract groups compared with the diabetic group and the diabetic + extract groups $[F(7,40)=53.25$, $P<0.001]$. The extract doses were expressed as $\mathrm{mg} / \mathrm{kg}$. ${ }^{* * *}, \# \#$, $\wedge \wedge \wedge$, and !!! as $P<0.001$.

\section{Evaluation of VEGF concentrations in serum}

Figure 2 shows the mean serum VEGF concentrations in the control group and the diabetic group. There was no significant difference between the diabetic group and the control group in the amount of serum VEGF [control $(255.17 \pm 3.544)$ and diabetic $(236.67 \pm 27.364)$ $(P>0.05)]$. Moreover, there was no significant difference between the control group and the extract groups in mean serum VEGF concentrations. The administration of the extract at doses of 200, 400, and $1000 \mathrm{mg} / \mathrm{kg}$ had no significant effect on the amount of serum VEGF in the extract groups in comparison to control group [control $(255.17 \pm 3.544)$ with extract $200[(235 \pm 2.608)(P>0.05)$, extract $400(255.83 \pm 4.498)(P>0.05)$, and extract 1000 $(254.67 \pm 10.269)(P>0.05)]$ and there was no significant difference between the diabetic group and the diabetic + extract groups in mean serum VEGF concentrations. The administration of the extract at doses of 200, 400, and 1000 $\mathrm{mg} / \mathrm{kg}$ had no significant effect on the amount of serum VEGF in the diabetic + extract groups in comparison with diabetic group [diabetic $(236.67 \pm 27.364)$ with diabetic + extract $200(232.83 \pm 27.766)(P>0.05)$, diabetic + extract $400(234.33 \pm 21.636)(P>0.05)$, and diabetic + extract $1000(235.67 \pm 17.959)(P>0.05)]$.

\section{Evaluation of capillary density in the heart}

Figure 3 shows the mean capillary density in the control and diabetic groups. Results showed a significant difference between the diabetic group and the control group in the capillary density [control $(83 \pm 4.899)$ and diabetic

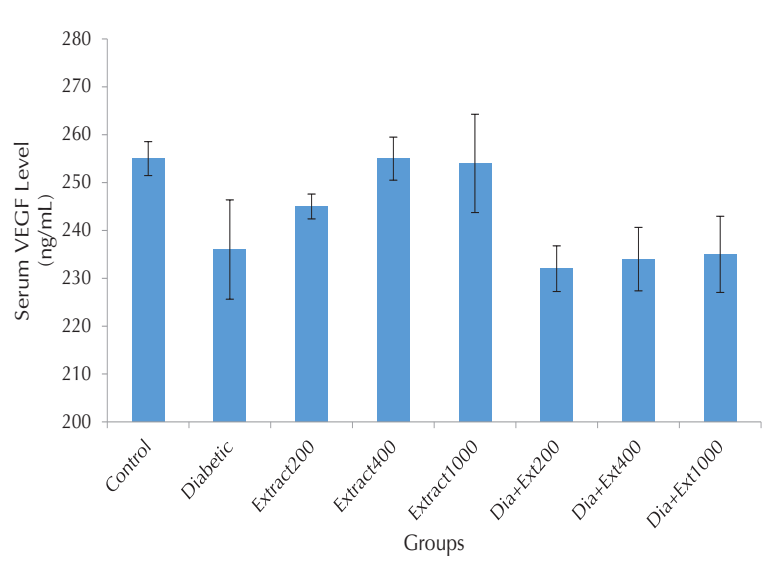

Figure 2. The Mean Serum VEGF Concentrations in the Control Group Compared with the Diabetic Group and Extract Groups, as well as the Diabetic Group Compared with the Diabetic + Extract Groups

Results showed that there was no significant difference between these groups. [control $(255.17 \pm 3.544)$ with diabetic $(236.67 \pm 27.364)(P>0.05)$, extract $200(235 \pm 2.608)(P>0.05)$, extract $400 \quad(255.83 \pm 4.498) \quad(P>0.05)$, and extract 1000 $(254.67 \pm 10.269)(P>0.05)$, as well as diabetic $(236.67 \pm 27.364)$ with diabetic + extract $200(232.83 \pm 27.766)(P>0.05)$, diabetic + extract $400(234.33 \pm 21.636)(P>0.05)$, and diabetic + extract 1000 $(235.67 \pm 17.959)(P>0.05)]$.

The extract doses were expressed as $\mathrm{mg} / \mathrm{kg}$. 


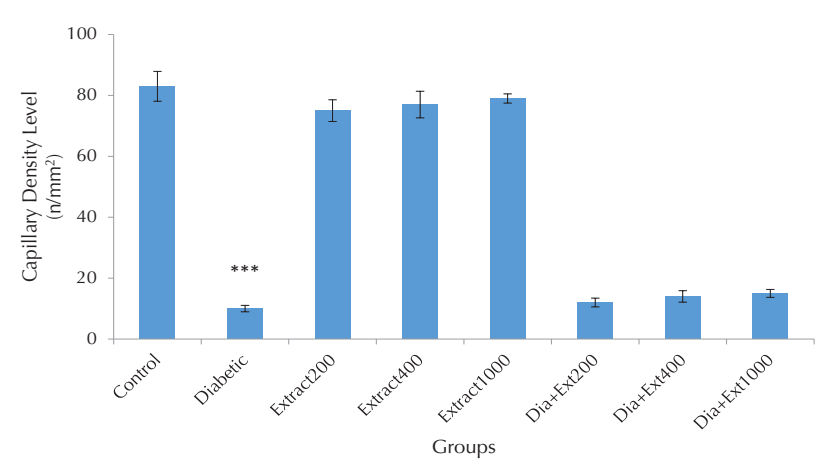

Figure 3. The Mean Capillary Density of the Heart Tissue in the Control Group Compared with the Diabetic Group and Extract Groups, and the Diabetic Group Compared with the Diabetic + Extract Groups.

These results showed a significant difference between the control and the diabetic groups. ${ }^{* * *}$ Statistically significant differences were observed in the diabetic group compared to the control group [control $(83 \pm 4.899)$ and diabetic $(10 \pm 1.065)(P<0.001)]$. Additionally, results showed that there were not significant differences between the control group and the extract groups and the diabetic group compared to the diabetic + extract groups [control $(83 \pm 4.899)$ with extract $200(75.33 \pm 3.565)(P>0.05)$, extract $400(77.83 \pm 4.385)$ $(P>0.05)$, and extract $1000(79.50 \pm 1.500)(P>0.05)$ and diabetic $(10 \pm 1.065)$ with diabetic + extract $200(12.50 \pm 1.455)(P>0.05)$, diabetic + extract $400(14.50 \pm 1.875)(P>0.05)$, and diabetic + extract $1000(15.17 \pm 1.302)(P>0.05)]$. The extract doses were expressed as $\mathrm{mg} / \mathrm{kg}$.

$(10 \pm 1.065)(P<0.001)]$. Additionally, findings showed no significant difference between the control and the extract groups in capillary density. In fact, the administration of extract at doses of 200, 400, and $1000 \mathrm{mg} / \mathrm{kg}$ had no significant effect on the capillary density of these groups [control $(83 \pm 4.899)$ with extract $200(75.33 \pm 3.565)$ $(P>0.05)$, extract $400 \quad(77.83 \pm 4.385) \quad(P>0.05)$, and extract $1000(79.50 \pm 1.500)(P>0.05)]$. Similarly, Figure 3 shows the mean capillary density in the diabetic and the diabetic + extract groups. Findings showed no significant difference in the capillary density between these groups and the administration of extract at doses of 200, 400, and $1000 \mathrm{mg} / \mathrm{kg}$ had no significant effect on the capillary density in these groups [diabetic $(10 \pm 1.065)$ with diabetic + extract $200(12.50 \pm 1.455)(P>0.05)$, diabetic + extract $400(14.50 \pm 1.875)(P>0.05)$, and diabetic + extract 1000 $(15.17 \pm 1.302) \quad(P>0.05)]$. Representative samples of histological sections are shown in Figures 4 to 6 .

\section{Discussion}

In this study, the cardiac capillary density was found to be reduced in the diabetic group compared to the control group, while no changes were observed in serum VEGF. Although oral treatment of rats with $R$. damascena Mill extract at 200, 400, and $1000 \mathrm{mg} / \mathrm{kg}$ doses increased the capillary density of the heart tissue in diabetic groups, this increase was not??? statistically significant in comparison with the diabetic group. Moreover, the capillary density in the normal group received extract was not significantly different from that in the control group. The findings of this study showed no significant change in serum VEGF of diabetic and extract group compared with the diabetic group as well as the groups received the extract as compared to the control group, which is consistent with another study (17). There are various chemical compounds in $R$. damascena Mill, including terpenes, glycosides, and flavonoids such as kaempferol and quercetin $(9,18)$. Studies have shown that flavonoids reduce angiogenesis by reducing

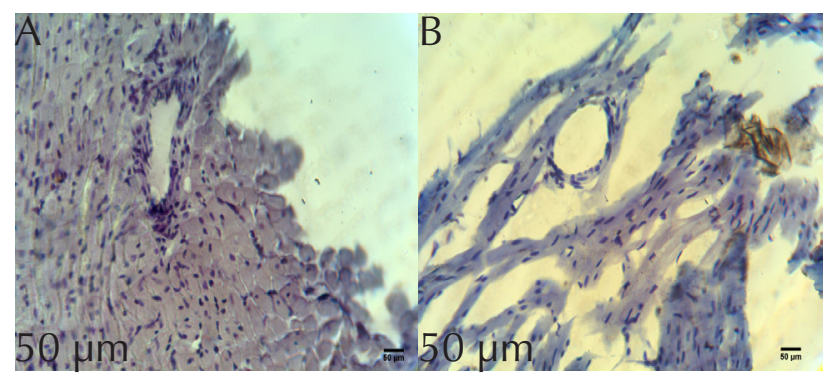

Figure 4. Representative photograph of the cross section of apex of the heart capillary density in experimental groups, original magnification: $\times$ 400. A) Heart tissue of the control group and $\mathbf{B}$ ) Heart tissue of the diabetic group. As shown in the figures, there is a significant decrease in capillary density in the diabetic group.
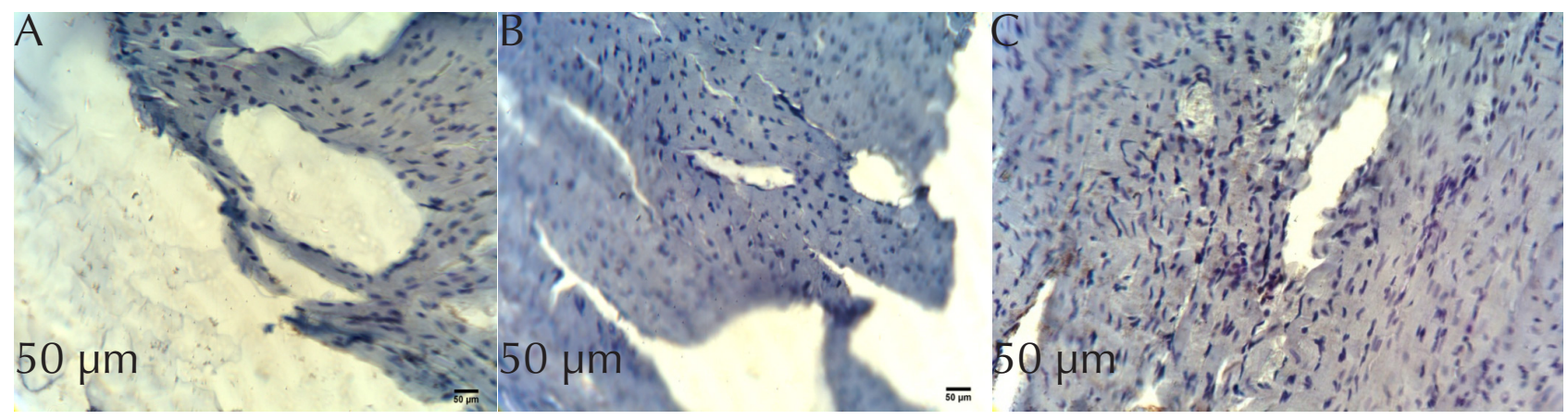

Figure 5. Representative Cross-sectional photograph of the cardiac capillary density in the experimental groups, original magnification: $\times 400$. A) Heart tissue of the extract group at a dose of $200 \mathrm{mg} / \mathrm{kg}$, B) Heart tissue of the extract group at a dose of $400 \mathrm{mg} / \mathrm{kg}$ and C) Heart tissue of the extract group at a dose of $1000 \mathrm{mg} / \mathrm{kg}$. As shown in the figures, there is no significant change in capillary density in the extract groups in comparison with control group. 


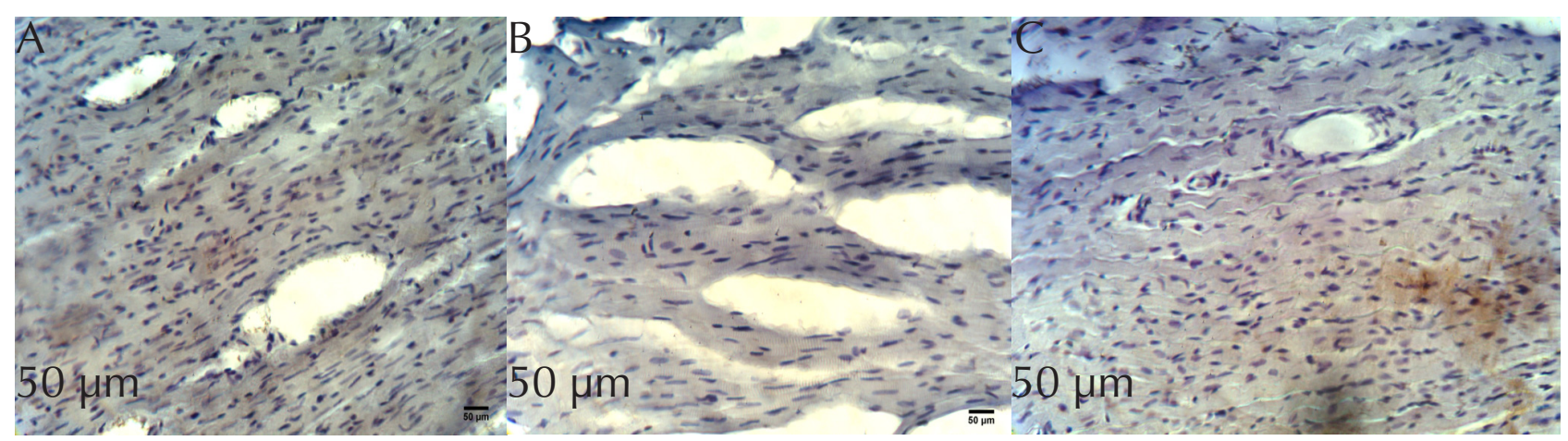

Figure 5. Representative Cross-sectional photograph of the cardiac capillary density in the experimental groups, original magnification: $\times 400$. A) Heart tissue of the extract group at a dose of $200 \mathrm{mg} / \mathrm{kg}$, B) Heart tissue of the extract group at a dose of $400 \mathrm{mg} / \mathrm{kg}$ and C) Heart tissue of the extract group at a dose of $1000 \mathrm{mg} / \mathrm{kg}$. As shown in the figures, there is no significant change in capillary density in the extract groups in comparison with control group.

the expression of VEGF or inhibiting the hypoxia-induced VEGF $(19,20)$. Another study has shown that quercetin induces antiangiogenic effects by inhibiting several stages of angiogenesis, such as the proliferation and migration of vascular endothelial cells, by reducing the expression and activity of matrix metalloproteinase-2, which is involved in the migration of vascular endothelial cells (21). The results of this study also showed that the oral administration of hydroalcoholic extract of $R$. damascena Mill at different doses increased capillary density in the heart of diabetic rats, while it reduced the serum VEGF concentration in the experimental groups compared to the control group, which was not statistically significant. According to previous studies, this finding is due to VEGF resistance to diabetesinduced vascular complications (17). Possible reasons for this include the type of diabetes induced (type I) in rats, which caused more severe complications and disability and less tolerance against diabetes. Therefore, the extract could not exert its effect in improving the complications of diabetes as it should. We can also refer to non-toxic oral doses used in this study that may not be the same as the dose of the extract, which can cause a significant change in the capillary density due to the presence of sufficient flavonoids. Moreover, the insignificant difference between the experimental groups may be due to short duration of extract administration (15). In addition, this study revealed that the treatment with $R$. damascena Mill extract at 200, 400 and $1000 \mathrm{mg} / \mathrm{kg}$ doses did not significantly increase the blood glucose levels of the extract groups compared to the control group and had no effect on the decrease of blood glucose levels in diabetic rats. However, its administration to the diabetic group that received extract at the specified doses reduced the blood glucose level at the end of the test (fourth week), which was not significant. Previous studies have shown that polysaccharides, flavonoids, polypeptides, and alkaloids in medicinal plants can justify glucose and lipid lowering properties (22,23). Moreover, several studies have reported the positive effect of antioxidants and antioxidant properties of medicinal plants (24). Some studies have shown that the administration of flavonoids increases glucose uptake by liver cells, adipose tissues, and muscles(25). The hypoglycemic effects of flavonoids can be partly attributed to the increased activity of hexokinase and glucokinase in the liver, as well as their insulin-like effect, thereby reducing the symptoms of diabetes mellitus (26). The lack of effect of the extract on the reduction of blood glucose in the present study may be due to the use of non-toxic doses, the amount of active ingredient, and the duration of the extract administration. It is also possible that active ingredients of $R$. damascena Mill have not entered the blood due to the use of non-toxic doses which were ineffective in lowering blood glucose. These substances have not been absorbed through oral administration due to the presence of some materials in this plant, or they have been metabolized in the liver and have created inactive metabolites. Another possible explanation is that the slight reduction in blood glucose achieved by receiving the extract, as indicated in the present review, is neutralized due to the presence of absorbable carbohydrates normally found in the extracts. It is also possible that blood glucose lowering substances along with their additives existed in $R$. damascena Mill extract to prevent blood glucose levels in the examined rats.

\section{Conclusion}

In brief, hydroalcoholic extract of $R$. damascena Mill used at the specified doses did not have a significant effect on blood glucose level, serum capillary density, and VEGF concentration in control and diabetic groups. Therefore, according to the results of this study, the type of diabetes, dose of administration, amount of active ingredient of the extract, and duration of the administration were found as the factors for the inefficiency of hydroalcoholic extract of $R$. damascena Mill in preventing cardiovascular complications caused by diabetes in rats. 
Conflict of Interests

The authors declare no conflict of interests associated with this publication.

\section{Ethical Considerations}

This article was derived from the research project approved by Hamadan University of Medical Sciences (approval code: IR.UMSHA.REC.1394.68).

\section{Acknowledgements}

The authors would like to express their gratitude to Dr. Arash Dehghan, Mohammad Rafiei, the Histology Laboratory of the Faculty of Medicine, the Pathology Laboratory of Besat Hospital, and the Neurophysiology Research Center for helping us to carry out this project. We thank the Vice-chancellor for Research and Technology of the Hamadan University of Medical Sciences for approving and supporting this research project (grant no. 9403191362) on 19/03/1394.

\section{References}

1. Karunakaran U, Park KG. A systematic review of oxidative stress and safety of antioxidants in diabetes: focus on islets and their defense. Diabetes Metab J. 2013;37(2):106-12. doi: 10.4093/dmj.2013.37.2.106.

2. Mehrabzadeh $M$, Pasalar $P$, Karimi $M$, Abdollahi $M$, Daneshpour M, Asadolahpour E, et al. Association between ELMO1 gene polymorphisms and diabetic nephropathy in an Iranian population. J Diabetes Metab Disord. 2015;15:43. doi: 10.1186/s40200-016-0265-3.

3. Carmeliet P, Jain RK. Angiogenesis in cancer and other diseases. Nature. 2000;407(6801):249-57. doi: 10.1038/35025220.

4. Zarei M, Khazaei M, Sharifi MR, Pourshanazari AA. Coronary angiogenesis during experimental hypertension: is it reversible? J Res Med Sci. 2011;16(3):269-75.

5. Martin A, Komada MR, Sane DC. Abnormal angiogenesis in diabetes mellitus. Med Res Rev. 2003;23(2):117-45. doi: 10.1002/med.10024.

6. Amin A, Choi SK, Galan M, Kassan M, Partyka M, Kadowitz P, et al. Chronic inhibition of endoplasmic reticulum stress and inflammation prevents ischaemia-induced vascular pathology in type II diabetic mice. J Pathol. 2012;227(2):165-74. doi: 10.1002/path.3960.

7. Silva NCC, Fernandes Júnior A. Biological properties of medicinal plants: a review of their antimicrobial activity. J Venom Anim Toxins Incl Trop Dis. 2010;16(3):402-13. doi: 10.18203/2319-2003.20163238.

8. Özkan G, Sagdiç O, Baydar NG, Baydar H. Note: antioxidant and antibacterial activities of Rosa damascena Mill flower extracts. Food Sci Technol Int. 2004;10(4):277-81. doi: 10.1177/1082013204045882.

9. Boskabady MH, Shafei MN, Saberi Z, Amini S. Pharmacological effects of Rosa damascena Mill. Iran J Basic Med Sci. 2011;14(4):295-307.

10. Kim JD, Liu L, Guo W, Meydani M. Chemical structure of flavonols in relation to modulation of angiogenesis and immuneendothelial cell adhesion. J Nutr Biochem. 2006;17(3):165-76. doi: 10.1016/j.jnutbio.2005.06.006.

11. Kolb H. Mouse models of insulin dependent diabetes: lowdose streptozocin-induced diabetes and nonobese diabetic (NOD) mice. Diabetes Metab Rev. 1987;3(3):751-78. doi: 10.1002/dmr.5610030308.

12. Hajhashemi V, Ghannadi A, Hajiloo M. Analgesic and antiinflammatory effects of Rosa damascena hydroalcoholic extract and its essential oil in animal models. Iran J Pharm Res. 2010;9(2):163-8.

13. Saxena M, Shakya AK, Sharma N, Shrivastava S, Shukla S. Therapeutic efficacy of Rosa damascena Mill. on acetaminophen-induced oxidative stress in albino rats. J Environ Pathol Toxicol Oncol. 2012;31(3):193-201. doi: 10.1615/jenvironpatholtoxicoloncol.v31.i3.10.

14. Hosseini M, Ghasemzadeh Rahbardar M, Sadeghnia HR, Rakhshandeh H. Effects of different extracts of Rosa damascena on pentylenetetrazol-induced seizures in mice. Zhong $\mathrm{Xi}$ Yi Jie He Xue Bao. 2011;9(10):1118-24. doi: 10.3736/ jcim20111013.

15. Ramezani R, Moghimi A, Rakhshandeh H, Ejtehadi $H$, Kheirabadi M. The effect of Rosa damascena essential oil on the amygdala electrical kindling seizures in rat. Pak J Biol Sci. 2008;11(5):746-51. doi: 10.3923/pjbs.2008.746.751.

16. Shibuya M. Structure and function of VEGF/VEGF-receptor system involved in angiogenesis. Cell Struct Funct. 2001;26(1):25-35. doi: 10.1247/csf.26.25.

17. Khazaei M, Fallahzadeh AR, Sharifi MR, Afsharmoghaddam $\mathrm{N}$, Javanmard SH, Salehi E. Effects of diabetes on myocardial capillary density and serum angiogenesis biomarkers in male rats. Clinics (Sao Paulo). 2011;66(8):1419-24. doi: 10.1590/ s1807-59322011000800019.

18. Oka N, Ikegami A, Ohki M, Sakata K, Yagi A, Watanabe N. Citronellyl disaccharide glycoside as an aroma precursor from rose flowers. Phytochemistry. 1998;47(8):1527-9. doi: 10.1016/S0031-9422(97)00526-8.

19. Mojzis J, Varinska L, Mojzisova G, Kostova I, Mirossay L. Antiangiogenic effects of flavonoids and chalcones. Pharmacol Res. 2008;57(4):259-65. doi: 10.1016/j.phrs.2008.02.005.

20. Ansó E, Zuazo A, Irigoyen M, Urdaci MC, Rouzaut A, Martínez-Irujo JJ. Flavonoids inhibit hypoxia-induced vascular endothelial growth factor expression by a HIF-1 independent mechanism. Biochem Pharmacol. 2010;79(11):1600-9. doi: 10.1016/j.bcp.2010.02.004.

21. Tan WF, Lin LP, Li MH, Zhang YX, Tong YG, Xiao D, et al. Quercetin, a dietary-derived flavonoid, possesses antiangiogenic potential. Eur J Pharmacol. 2003;459(2-3):25562. doi: 10.1016/s0014-2999(02)02848-0.

22. Murray-Lyon IM, Eddleston AL, Williams R, Brown M, Hogbin BM, Bennett A, et al. Treatment of multiple-hormone-producing malignant islet-cell tumour with streptozotocin. Lancet. 1968;2(7574):895-8. doi: 10.1016/s0140-6736(68)91058-1.

23. Brahmachari G. Bio-flavonoids with promising antidiabetic potentials: a critical survey. In: Tiwari VK, Mishra BB, eds. Opportunity, Challenge and Scope of Natural Products in Medicinal Chemistry. 1st ed. Research Signpost; 2011. p. 187212.

24. El-Far YM, Zakaria MM, Gabr MM, El Gayar AM, El-Sherbiny IM, Eissa LA. A newly developed silymarin nanoformulation as a potential antidiabetic agent in experimental diabetes. Nanomedicine (Lond). 2016;11(19):2581-602. doi: 10.2217/ nnm-2016-0204.

25. Su HC, Hung LM, Chen JK. Resveratrol, a red wine antioxidant, possesses an insulin-like effect in streptozotocininduced diabetic rats. Am J Physiol Endocrinol Metab. 2006;290(6):E1339-46. doi: 10.1152/ajpendo.00487.2005.

26. Vessal $M$, Hemmati $M$, Vasei $M$. Antidiabetic effects of quercetin in streptozocin-induced diabetic rats. Comp Biochem Physiol C Toxicol Pharmacol. 2003;135C(3):357-64. doi: 10.1016/ s1532-0456(03)00140-6. 